\title{
Erratum to: Every Family: A Population Approach to Reducing Behavioral and Emotional Problems in Children Making the Transition to School
}

\author{
Matthew R. Sanders • Alan Ralph • \\ Kate Sofronoff • Paul Gardiner • \\ Rachel Thompson - Sarah Dwyer - Kerry Bidwell
}

Published online: 2 September 2014

(C) Springer Science+Business Media New York 2014

\section{Erratum to: J Primary Prevent (2008) 29:197-222 DOI 10.1007/S10935-008-0139-7}

An author (Matthew R. Sanders) of the original publication wishes to include the following:

Conflict of interest The Triple P-Positive Parenting Program is owned by the University of Queensland. The University through its main technology transfer company, UniQuest Pty Ltd, has licensed Triple P International Pty Ltd to publish and disseminate the program world wide. Royalties stemming from published Triple $\mathrm{P}$ resources are distributed in accordance with the University's intellectual property policy and flow to the Parenting and Family Support Centre; School of Psychology; Faculty of Health and Behavioural Sciences; and contributory authors. No author has any share or ownership in Triple P International Pty Ltd. Matthew Sanders is the founder and an author on various Triple $\mathrm{P}$ programs and a consultant to Triple $\mathrm{P}$ International. Alan Ralph is the Head of Training for Triple $\mathrm{P}$ International.
The online version of the original article can be found under doi:10.1007/s10935-008-0139-7.

M. R. Sanders $(\bowtie) \cdot$ A. Ralph · K. Sofronoff . P. Gardiner · R. Thompson

Parenting and Family Support Centre, School of

Psychology, The University of Queensland,

Brisbane 4072, QLD, Australia

e-mail: matts@psy.uq.edu.au

S. Dwyer · K. Bidwell

Queensland Divisions of General Practice, Brisbane,

QLD, Australia 